\title{
Status epilepticus induced by treatment with dopamine agonist therapy for giant prolactinoma: a case report
}

\author{
Motofumi Koguchi, Yukiko Nakahara* (D), Ryo Ebashi, Atsushi Ogata, Shoko Shimokawa, Jun Masuoka and \\ Tatsuya Abe
}

\begin{abstract}
Background: Dopamine agonists are the standard first-line medical therapy for prolactinoma. We report a rare case of giant prolactinoma with a first epileptic seizure due to rapid reduction of the tumor as a complication of dopamine agonist therapy.

Case presentation: A 27-year-old Japanese man presented to our institution with a history of visual disturbance for 1 year and general fatigue for 3 months. Magnetic resonance imaging showed a tumor that arose from the pituitary and extended to the bilateral anterior skull base, the clivus, and the cavernous sinus, with compression of the optic chiasm and the bilateral frontal and temporal lobes. On the basis of the patient's serum concentration of prolactin, we diagnosed a prolactinoma and started dopamine agonist therapy with cabergoline. The patient had a general seizure immediately after starting dopamine agonist therapy and required general anesthetic treatment following the rapid reduction of the tumor. We speculated that the rapid reduction of the tumor resulted in the retraction of the surrounding brain structure, and the epileptic seizure was then induced by dopamine agonist therapy.

Conclusions: We report a rare case of giant prolactinoma with a first epileptic seizure immediately after the initiation of dopamine agonist therapy. Clinicians need to be aware that the rapid reduction of a giant prolactinoma by dopamine agonist therapy may cause an epileptic seizure.
\end{abstract}

Keywords: Epilepsy, Giant prolactinoma, Cabergoline, Case report

\section{Background}

Prolactin (PRL)-secreting pituitary adenomas (PRLomas) are the most common pituitary secreting tumors, accounting for $32-45 \%$ of all pituitary tumors [1-3]. Micro-PRLomas are more common in females, whereas macro-PRLomas are more common in males $[1,3]$. Although there is no consensus on the definition of giant PRLomas, some studies have defined giant PRLoma as measuring more than $4 \mathrm{~cm}[4,5]$. In addition to pituitary hormone abnormalities, giant PRLomas cause several symptoms, such as visual field defects by compression of the optic chiasm, cranial nerve palsies by extension into the cavernous sinus, obstructive hydrocephalus, epilepsy by temporal lobe extension, and dementia by frontal lobe extension.

\footnotetext{
* Correspondence: nakahara@cc.saga-u.ac.jp

Department of Neurosurgery, Faculty of Medicine, Saga University, 5-1-1 Nabeshima, Saga 849-8501, Japan
}

Dopamine agonist (DA) therapy is the standard treatment for PRLoma. In previous reports, DA therapy was the first-line medical treatment even for giant PRLomas, because normalization of PRL and significant tumor shrinkage were achieved in the majority of cases $[4,5]$. The most common side effects of DA therapy are headache, nausea and vomiting, orthostatic hypotension, and depression. Attention also needs to be paid to rare complications, such as cerebrospinal fluid rhinorrhea $[6,7]$ and optic chiasm herniation [8-10]. However, medical treatment for PRLomas has not been known to cause seizure attacks as a side effect of DA therapy. In this article, we present a rare case of a patient with epileptic seizures immediately after the initiation of DA therapy with cabergoline $(\mathrm{CAB})$. We review the previous literature and suggest the mechanism of this complication. 


\section{Case presentation}

A 27-year-old Japanese man with mild mental developmental retardation presented with a 1-year history of bilateral visual impairment as well as a 3-month gradually progressive general fatigue. He had no history of epileptic seizures. Neurological examination revealed blindness of the left eye, half-blindness of the right eye on the ear side, and cognitive dysfunction according to the Mini Mental State Examination 21/30. Fundus examination revealed no papilledema. Magnetic resonance imaging (MRI) revealed a $77 \times 63 \times 85-\mathrm{mm}$ tumor that arose from the pituitary and extended bilaterally through the anterior skull base, the clivus, and the cavernous sinus, with compression of the optic chiasm and the bilateral frontal and temporal lobes (Figs. 1 and $3 \mathrm{a}-\mathrm{c}$ ). The patient was administered antiepileptics, such as $1000 \mathrm{mg} /$ day levetiracetam, for prevention of seizure attack. His hormone profile showed hyperprolactinemia $25,270.0 \mathrm{ng} / \mathrm{ml}(3.6-12.8 \mathrm{ng} / \mathrm{ml})$ and dysfunction of the other pituitary hormones (testosterone, $<0.04 \mathrm{ng} / \mathrm{ml}[1.3-8.7 \mathrm{ng} / \mathrm{ml}]$; follicle-stimulating hormone, $0.54 \mathrm{mIU} / \mathrm{ml}[2.0-8.3 \mathrm{mIU} / \mathrm{ml}]$; luteinizing hormone, $<0.10 \mathrm{mIU} / \mathrm{ml}[0.79-5.7 \mathrm{mIU} / \mathrm{ml}]$; thyroid-stimulating hormone, $4.94 \mu \mathrm{IU} / \mathrm{ml}[0.5-5.0 \mu \mathrm{IU} / \mathrm{ml}]$; free thyroxine $4,0.6$ $\mathrm{ng} / \mathrm{dl}[0.9-1.7 \mathrm{ng} / \mathrm{dl}]$; growth hormone, $0.22 \mathrm{ng} / \mathrm{ml}[0.0-2.5$ $\mathrm{ng} / \mathrm{ml}]$; and adrenocorticotropic hormone, $1.7 \mathrm{pg} / \mathrm{ml}[7.2-$ $63.3 \mathrm{pg} / \mathrm{ml}]$ ) (Table 1). The patient received a diagnosis of a giant PRLoma with hypopituitarism. We started DA therapy with $C A B 0.25 \mathrm{mg}$ once per week, supplemented by daily oral hydrocortisone.

Eight days after starting DA therapy, the patient had a tonic-clonic seizure with loss of consciousness that developed into status epilepticus. Incubation and general anesthetic therapy were required. The patient was
Table 1 Hormone profile showing hyperprolactinemia and dysfunction of the other pituitary hormones before treatment

\begin{tabular}{lll}
\hline Hormone & Value & Normal reference range \\
\hline PRL & $25,270.0 \mathrm{ng} / \mathrm{ml}$ & $(3.6-12.8)$ \\
Testosterone & $<0.04 \mathrm{ng} / \mathrm{ml}$ & $(1.3-8.7)$ \\
FSH & $0.54 \mathrm{mlU} / \mathrm{ml}$ & $(2.0-8.3)$ \\
LH & $<0.10 \mathrm{mlU} / \mathrm{ml}$ & $(0.79-5.7)$ \\
TSH & $4.94 \mu \mathrm{IU} / \mathrm{ml}$ & $(0.5-5.0)$ \\
fT4 & $0.6 \mathrm{ng} / \mathrm{dl}$ & $(0.9-1.7)$ \\
GH & $0.22 \mathrm{ng} / \mathrm{ml}$ & $(0.0-2.5)$ \\
ACTH & $15.4 \mathrm{pg} / \mathrm{ml}$ & $(7.2-63.3)$
\end{tabular}

Abbreviations: ACTH Adrenocorticotropic hormone, FSH Follicle-stimulating hormone, fT4 Free thyroxine, GH Growth hormone, LH Luteinizing hormone, PRL Prolactin

admitted to the intensive care unit. An electroencephalographic examination was continuously performed; however, no findings of epileptic changes were found after general anesthesia. There was no abnormality in the laboratory analysis that may have led to status epilepticus. The patient's blood level of PRL markedly decreased from $25,270.0$ to $948.2 \mathrm{ng} / \mathrm{ml}$. MRI revealed significant reduction of the tumor in a short period without pituitary apoplexy, including hemorrhagic or ischemic change (Figs. 2 and 3c, e, f). According to the significant reduction of the tumor, the bilateral mesial temporal lobes returned to medial position. Further, a hyperintense area in left frontal lobe appeared on T2 -weighted images (Fig. 3). Because of the possibility that the epileptic seizures were induced by the rapid shrinkage of the tumor, we suspended DA therapy until the seizures were under control with the antiepileptic drug

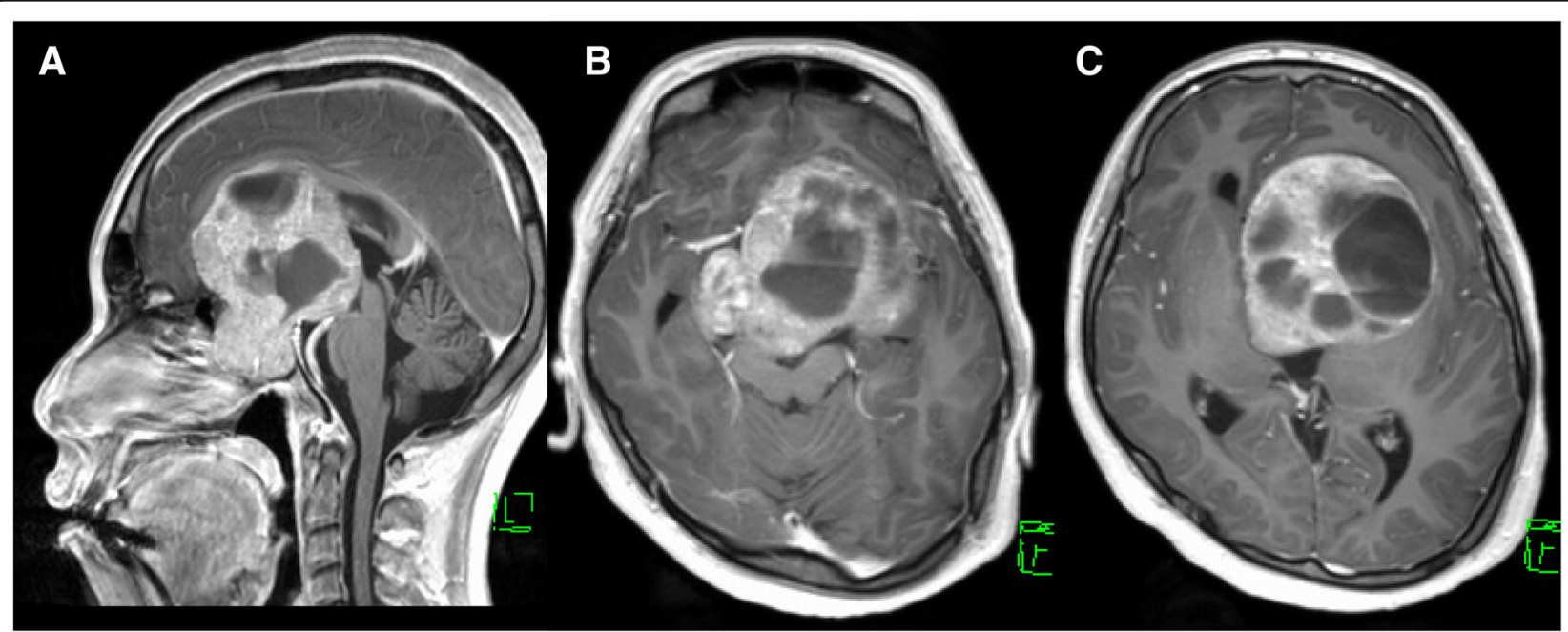

Fig. 1 Gadolinium-enhanced T1-weighted images before the initiation of dopamine agonist therapy. a Sagittal view. b and c Axial images Magnetic resonance imaging showed a tumor that arose from the pituitary and extended bilaterally through the anterior skull base, the clivus, and the cavernous sinus 


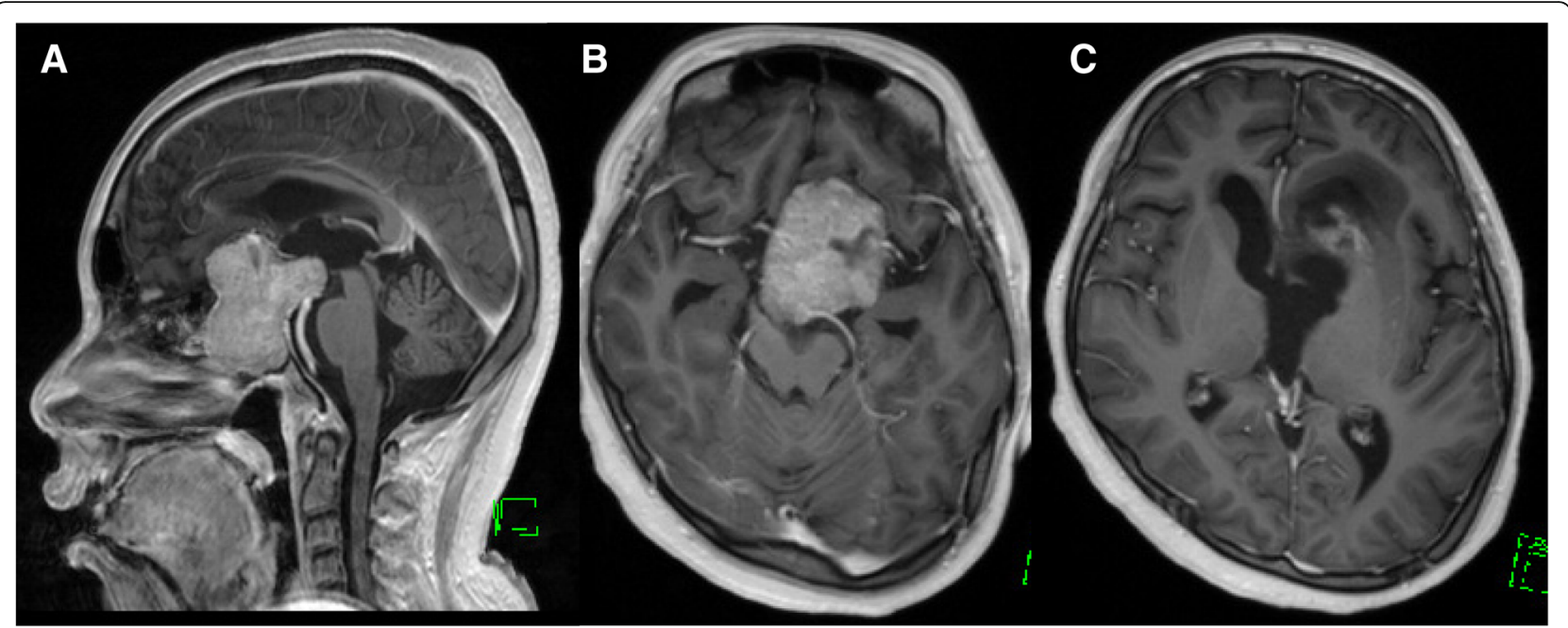

Fig. 2 Gadolinium-enhanced T1-weighted images after dopamine agonist (DA) therapy. a Sagittal view. b and c Axial images. Tumor reduced significantly after the initiation of DA therapy with cabergoline

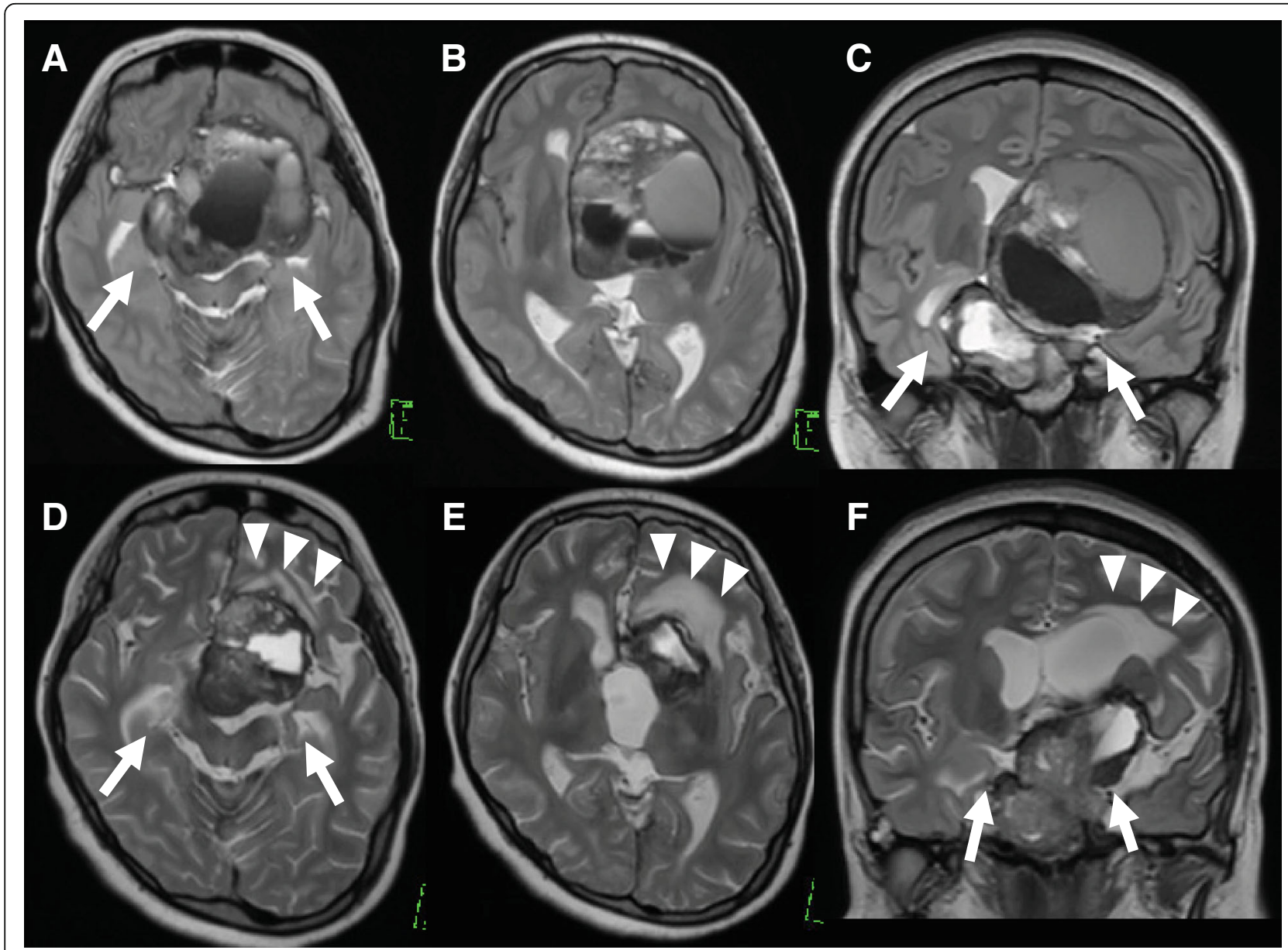

Fig. 3 T2-weighted images (T2WI) before and after dopamine agonist therapy. a-c Before treatment. $\mathbf{d}-\mathbf{f}$ After initial treatment. Following significant reduction of the tumor, the bilateral mesial temporal lobes returned to medial position (white arrows), and a hyperintense area on T2WI appeared in the left frontal lobe (white arrowheads) 
levetiracetam $2000 \mathrm{mg} /$ day. General anesthetic therapy was required for the control of seizures for 2 weeks. After 4 weeks, we resumed DA therapy with extremely low doses of CAB. Both the level of PRL and the tumor size were gradually reduced without further seizures. The patient was able to return to daily life with medication of antiepileptics and oral hydrocortisone and levothyroxine.

\section{Discussion}

Giant PRLomas cause neurologic complications due to their massive extension into the surrounding structures. The aim of the treatment of giant PRLomas is rapid improvement of neurologic symptoms, such as visual disorders, increased intracranial pressure, and palsies of the cranial nerves. The treatment is required to reduce the size of the tumor remarkably. There are several therapeutic approaches, including DA therapy, surgery, radiotherapy, and combinations of these therapies. We chose DA therapy alone in our patient's case for two reasons: (1) According to previous reports, DA is the first-line medical treatment even for giant PRLomas, and (2) surgical resection may cause severe complications in important surrounding structures $[4,5]$. $C A B$ has emerged as a drug for DA therapy owing to its excellent efficacy and safety. Headache, nausea and vomiting, orthostatic hypotension, depression, and cerebrospinal fluid rhinorrhea are known as common side effects of DA therapy [6, 7]. However, a small proportion of patients have rare complications, including herniation of the optic chiasm, each cerebral lobe, and the brainstem [8-10]. Moles Herbera et al. reported a giant PRLoma showing pons herniation into the skull base caused by tumor shrinkage after DA therapy [11]. In addition, some authors reported cases of frontal lobe herniation as a rare complication of DA therapy (Table 2) [8-10, 12].

According to the package insert of $\mathrm{CAB}$, neurologic and psychiatric side effects were somnolence, aggression, and psychotic behavior. An increase in the risk of epilepsy has not been known as a side effect of CAB. Most previous reports of PRLoma described epileptic seizures as initial symptoms before treatment. Deepak et al. reported that epilepsy often occurred in patients with invasive macro-PRLomas and that DA therapy could reduce the frequency of seizures and the doses of antiepileptic drugs [12].

In our patient, however, epileptic seizures occurred immediately after DA therapy for giant PRLoma without a previous history of seizures. The mechanism of the epileptic seizure in our patient is speculative and might be multifocal. On the basis of his clinical course, we concluded that the rapid reduction of the tumor by DA therapy, resulting in retraction of brain matter, especially the temporal lobe around the tumor, could have been the mechanism of the epileptic seizures. This mechanism is a known cause of brain herniation with DA therapy for giant PRLomas $[8,9,11]$. The appearance of a hyperintense area in left frontal lobe on T2-weighted images may support our hypothesis of the pathogenic mechanisms of the epileptic seizure in our patient. Clinicians should be aware that DA therapy for PRLoma which is effective therapy, can induce epileptic seizures. Furthermore, medical therapies and chemotherapies with excellent efficacy for brain tumors, such as germinomas, may be a risk factor for epileptic seizure as a side effect following rapid reduction of the tumor, similarly to DA therapy for PRLoma.

\section{Conclusions}

We report a rare case of a patient with giant PRLoma with epileptic seizures immediately after the initiation of DA therapy with CAB. It is possible that rapid tumor reduction induces epileptic seizures by the same mechanism as brain herniation. Even if there is no history of epilepsy, clinicians need to be aware of epileptic seizures during DA therapy for giant PRLomas.

Table 2 Reported cases of complication of dopamine agonist therapy for prolactinoma

\begin{tabular}{|c|c|c|c|c|c|}
\hline \multirow[t]{2}{*}{ Author (year) [reference] } & \multirow{2}{*}{$\begin{array}{l}\text { Patient age } \\
\text { (years)/sex }\end{array}$} & \multirow{2}{*}{$\begin{array}{l}\mathrm{PRL}(\mu \mathrm{g} / \mathrm{L}) \text { at } \\
\text { diagnosis }\end{array}$} & \multirow{2}{*}{$\begin{array}{l}\text { CAB dosage } \\
\text { (mg/week) }\end{array}$} & \multicolumn{2}{|c|}{ Complication of DA therapy } \\
\hline & & & & Location of herniation & Symptoms \\
\hline Papanastasiou et al. (2014) [8] & $42 / M$ & 2000 & 1.5 & Optic chiasma & Visual field loss \\
\hline Dhanwal et al. (2011) [9] & $36 / M$ & 183 & 1.0 & $\begin{array}{l}\text { Frontal lobe } \\
\text { and optic chiasma }\end{array}$ & $\begin{array}{l}\text { Visual field loss, } \\
\text { seizure }\end{array}$ \\
\hline \multirow[t]{3}{*}{ Raverot et al. (2009) [10] } & $64 / M$ & 1785 & 1.0 & \multirow[t]{3}{*}{ Optic chiasma } & \multirow[t]{3}{*}{ Visual field loss } \\
\hline & $30 / M$ & 660 & 3.0 & & \\
\hline & $57 / M$ & 482 & 3.0 & & \\
\hline Herbera et al. (2015) [11] & $59 / \mathrm{M}$ & 1108 & 1.0 & Pons & $\begin{array}{l}\text { Dysarthria, a } \\
\text { left hemiplegia }\end{array}$ \\
\hline
\end{tabular}




\section{Abbreviations}

ACTH: Adrenocorticotropic hormone; CAB: Cabergoline; DA: Dopamine agonist; FSH: Follicle-stimulating hormone; fT4: Free thyroxine; GH: Growth hormone; LH: Luteinizing hormone; MRI: Magnetic resonance imaging: PRL: Prolactin; PRLoma: Prolactinoma; T2WI: T2-weighted images

\section{Acknowledgements}

The authors thank Enago (https://www.enago.jp/) for the English language review.

\section{Funding}

The authors declare that there are no conflicts of interest associated with this report.

\section{Availability of data and materials}

The dataset supporting the conclusions of this article is included within the article.

\section{Authors' contributions}

MK reported the case and wrote the manuscript. RE and YN performed the management of the patient. YN helped in drafting the manuscript. AO, SS, $\mathrm{JM}$, and TA participated in revising the manuscript critically. All authors read and approved the final manuscript.

\section{Ethics approval and consent to participate}

Not applicable.

\section{Consent for publication}

Written informed consent was obtained from the patient for publication of this case report and any accompanying images. A copy of the written consent is available for review by the Editor-in-Chief of this journal.

\section{Competing interests}

The authors declare that they have no competing interests.

\section{Publisher's Note}

Springer Nature remains neutral with regard to jurisdictional claims in published maps and institutional affiliations.

Received: 1 November 2018 Accepted: 29 November 2018

Published online: 20 January 2019

\section{References}

1. Ciccarelli A, Daly AF, Beckers A. The epidemiology of prolactinomas. Pituitary. 2005;8:3-6.

2. Gillam MP, Molitch ME, Lombardi G, Colao A. Advances in the treatment of prolactinomas. Endocr Rev. 2006;27:485-534.

3. Tjörnstrand A, Gunnarsson K, Evert M, Holmberg E, Ragnarsson O, Rosén T, et al. The incidence rate of pituitary adenomas in western Sweden for the period 2001-2011. Eur J Endocrinol. 2014;171:519-26.

4. Maiter D, Delgrange E. Therapy of endocrine disease: the challenges in managing giant prolactinomas. Eur J Endocrinol. 2014;170:213-27.

5. Moraes AB, Marques Dos Santos Silva C, Vieira Neto L, Gadelha MR. Giant prolactinomas: the therapeutic approach. Clin Endocrinol. 2013; 79:447-56.

6. Leong KS, Foy PM, Swift AC, Atkin SL, Hadden DR, MacFarlane IA. CSF rhinorrhoea following treatment with dopamine agonists for massive invasive prolactinomas. Clin Endocrinol. 2000;52:43-9.

7. Prague JK, Ward CL, Mustafa OG, Whitelaw BC, King A, Thomas NW, et al. Delayed presentation of late-onset cerebrospinal fluid rhinorrhoea following dopamine agonist therapy for giant prolactinoma. Endocrinol Diabetes Metab Case Rep. 2014;2014:140020.

8. Papanastasiou L, Fountoulakis S, Pappa T, Liberopoulos K, Malliopoulos D, Markou A, et al. Brain and optic chiasmal herniation following cabergoline treatment for a giant prolactinoma: wait or intervene? Hormones. 2014;13:290-5.

9. Dhanwal DK, Sharma AK. Brain and optic chiasmal herniations into sella after cabergoline therapy of giant prolactinoma. Pituitary. 2011;14:384-7.
10. Raverot G, Jacob M, Jouanneau E, Delemer B, Vighetto A, Pugeat M, et al. Secondary deterioration of visual field during cabergoline treatment for macroprolactinoma. Clin Endocrinol. 2009;70:588-92.

11. Moles Herbera J, Rivero Celada D, Montejo Gañan I, Fustero de Miguel D, Fuentes Uliaque C, Vela Marín AC. Pons herniation into skull base after cabergoline therapy of giant prolactinoma. Pituitary. 2015;18:68-71.

12. Deepak D, Daousi C, Javadpour M, MacFarlane IA. Macroprolactinomas and epilepsy. Clin Endocrinol. 2007;66:503-7.

\section{Ready to submit your research? Choose BMC and benefit from:}

- fast, convenient online submission

- thorough peer review by experienced researchers in your field

- rapid publication on acceptance

- support for research data, including large and complex data types

- gold Open Access which fosters wider collaboration and increased citations

- maximum visibility for your research: over $100 \mathrm{M}$ website views per year

At BMC, research is always in progress.

Learn more biomedcentral.com/submissions 